\title{
COMERCIANTES DE ORIGEN CASTELLANO EN LEÓN: LAS FAMILIAS PABLOS-SALÁN-RODRÍGUEZ Y HERNÁNDEZ DE MEDINA-FERNÁNDEZ (1700-1850)
}

\author{
Juan Manuel Bartolomé Bartolomé \\ Universidad de León
}

Un fenómeno frecuente según la historiografía es el carácter exógeno de gran parte de los hombres de negocios, comerciantes, emplazados en las ciudades españolas en la Edad Moderna, particularmente el siglo XVIII'. En el caso concreto que nos ocupa, la ciudad de León, ya hemos analizado en anteriores aportaciones la relevante presencia y trayectoria social de familias de origen catalán ${ }^{2}$. Ahora le toca el turno a los comerciantes de origen castellano que se establecieron en la ciudad de León en el setecientos.

Ante la ausencia de archivos privados de estas familias burguesas nos hemos basado fundamentalmente en el cruzamiento de fuentes (archivos parroquiales, pleitos judiciales y especialmente protocolos notariales) para poder reconstruir las trayectorias generacionales de estas familias y al mismo tiempo poder estudiar el negocio comercial en el siglo XVIII y primera mitad del siglo XIX ${ }^{3}$.

1. Es lo que ocurre por ejemplo en Navarra y Vitoria donde la oleada fue más intensa en la segunda mitad del siglo XVIII. Azcona Guerra, A. Ma., Comercio y comerciantes en la Navarra del siglo XVIII , Navarra, 1996, págs. 239-241. Angulo Morales, A., Del éxito en los negocios al fracaso del Consulado: la formación de la burguesía mercantil de Vitoria (1670-1840), Bilbao, 2000, p. 90.

2. Bartolomé Bartolomé, J. M., "Hacer negocio en León: las familias catalanas Jolís y BunellSelva y sus estrategias (1700-1850)". Comunicación presentada al VII Congreso de la Asociación de Demografía Histórica, Granada, 2004. Sesión paralela "Movilidad geográfica, movilidad social: movimientos migratorios y reproducción social en la España moderna (siglos XVI-XVIII).

3. Ya en 1976 el profesor Paul Butel señaló que la institución familiar era una de las ópticas más adecuadas para el estudio del negocio comercial en el siglo XVIII. Butel, P., "Comportements familiaux dan le négoce bordelais au XVIIle siècle", en Annales du midi, pp. 139-157. 
De este modo, a través de una metodología de estudio social dinámica, no hermética ${ }^{4}$, donde el papel de la familia es de gran relevancia como intermediación entre el individuo y la comunidad ${ }^{5}$, nos proponemos dar respuesta a los siguientes objetivos: en primer lugar, qué mecanismos fueron los que se utilizaron para poder establecerse como hombres de negocio en León. En segundo lugar, estudiar la estructura de sus fortunas, prestando especial atención al balance económico familiar y a la orientación de sus negocios. También se tendrá en cuenta el grado de permeabilidad ante las nuevas coyunturas. En tercer lugar, adentrarnos en sus condiciones y estilo de vida, sus pautas de consumo y sus actitudes ante la muerte. En cuarto lugar, la familia como forma de articulación y gestión de los patrimonios: sus estrategias mercantiles, matrimoniales, hereditarias, etc ${ }^{6}$. Y finalmente, tampoco olvidaremos la reconstrucción de las trayectorias personales o biografías de estas familias, ya que es a través de las mismas como podemos acercarnos a los objetivos planteados y a las estrategias diseñadas para poder conseguir y consolidar su promoción patrimonial y social.

\section{La Familia Pablos-Rodríguez}

a) Orígenes y asentamiento en León

El 7 de diciembre de 1780 tiene lugar el casamiento en la parroquia de la esposa, San Martín de la ciudad de León, entre $M^{a}$ Antonia Rodríguez de Brizuela y José

4. Las formas rígidas de clasificación social de las sociedades del Antiguo Régimen, donde sólo los grandes cambios estructurales obligaban a una reorganización radical fueron criticadas por Levi, G., "Carrières d' artisans et marché du travail à Turín (XVIII-XIX siècles). Annales ESC, novembre-décembre, 1990, 6, pp. 1351-1364. Últimamente también ha vuelto a insistir en este carácter más abierto y dinámico de las sociedades del Antiguo Régimen Chacón Jiménez, F., "Historia de grupos: parentesco, familias, clientelas, linajes", en Historia Social y Ciencias Sociales, Santiago Castillo y Roberto Fernández (coordinadores), Lleida, 2001, p. 174.

5. Entre los trabajos que optan por este análisis más dinámico se pueden citar los de Rey, M., "Communauté et individu: I'amitié comme lien social á la Renaissance", en Revue d' Historire Moderne et Contemporaine, XXXVIII, 1991, pp. 617-625; Chumbohm, J., "Quelques problemes de micro-histoire d'une société locales. Constuction de liens sociaux dans la paroisse de Belm (17e.19e siècles)", en Annales HSS, juillet-août, 1995, 4, pp. 755-802; Imicoz Benuza, J.M., (ed.), Élites, Poder y Red Social, Bilbao, 1996, pp. 13-49; Cristóbal Maretín, A., "amistad, parentesco y patronazgo: redes vinculares y servidores inquisitoriales en el tribunal de Logroño. Siglo XVII", en Historia Social, 17, 1993, pp. 21-32; García González, F., Las estrategias de la diferencia. Familia y reproducción social en la sierra (Alcaraz, siglo XVIII) , Madrid, 2001.

6. Este papel de la familia en la gestión y articulación de los grandes patrimonios ha sido abordado ya por la historiografía europea. Ver trabajos de Davis, J.C., A Venetian Family and his Fortuna, 1500-1900. The donà and teh conservation of Their Wealth, Philadelfia, 1987; Malanima, P., Ricardi de firenze. Una famiglia e un parimonio nella Toscana dei Medici, Firenze, 1977; Wolf, J.S., Domestic stretegies: work and family in france and Italy, 1600-1800, Cambridge, 1991; Dedieu. J.P. y Windler, C., "la familia: una clave para entender la historia política. El ejemplo de la España moderna", en Studia Historica. Historia Moderna. Vol. 18, pp. 201-233. Casado, H. y Robledo, R., (edi.), Fortuna y negocios. Formación y gestión de los grandes patrimonios patrimoniales (s. XVI-XX), Valladolid, 2002. 
Pablos Salán’. Ella era soltera, natural y vecina de León, hija del primer matrimonio entre don Francisco Rodríguez de Brizuela y doña Clara Blanco, los cuales tenían como actividad principal el comercio de textiles. Una vez que muere su primer marido, don Francisco Rodríguez de Brizuela, la viuda buscará un casamiento rápido con el objetivo de poder seguir al frente de sus negocios y así se casará con Domingo Manuel Díez ${ }^{8}$. El resultado fue muy favorable ya que cuando fallece doña Clara Blanco, en 1801, el patrimonio familiar asciende a la suma de 228.108 reales de los cuales la casi totalidad son líquidos ya que el pasivo es de sólo 3.484 reales $^{9}$. En definitiva, los bienes gananciales conseguidos durante el matrimonio representan 221.310 reales, el 97\% del total patrimonial. Además, se trata de un patrimonio asentado fundamentalmente en el negocio comercial, como lo demuestra por una parte, la escasa presencia de los bienes raíces y semovientes $\left(\right.$ ganadería $^{10}$ ) y el aplastante predominio de los bienes mobiliarios. Y por otra parte, como van a ser los conceptos ligados directamente a la actividad comercial los de mayor importancia y valoración dentro de los bienes mobiliarios. Así, el stock de géneros de comercio constituirá la cantidad más alta, con 150.805 reales, un $84 \%$ de los bienes mobiliarios seguido a muy larga distancia por las deudas a favor del comercio, 14.283 reales y un $7,9 \%$ y el dinero en efectivo, un $2,8 \%{ }^{11}$.

En cuanto a la procedencia del marido, don José Pablos Salán, no es leonesa sino castellana, de Villada, una localidad de la provincia de Palencia, por otra parte, muy cercana a León. Desconocemos las razones que indujeron al enlace matrimonial con este pretendiente foráneo no sólo geográficamente sino también al margen del núcleo de familias influyentes de la ciudad y sociedad leonesa, pero lo cierto es que, como ya se ha señalado, en 1780 se realiza el matrimonio con este vecino soltero de Villada ${ }^{12}$.

\section{b) La familia y su dinámica}

\section{b.1. Fase de unión matrimonial: el éxito comercial}

El nuevo matrimonio se mantuvo unido durante un total de 32 años, desde 1780 que fue cuando se produjo el matrimonio hasta la muerte del marido en

7. Archivo Parroquia de San Martín.(A.P.S.M.). Libro de Casados № 5 (1763-1800).

8. Casamiento totalmente interesado como lo demuestra que él sólo aportó al mismo la cantidad de tan sólo 830 reales y en cambio la viuda fundamentalmente el comercio valorado en 5.977 reales. Archivo Histórico Provincial de León (A.H.P.L.), Juan de Dios Fernández, Caja 944.

9. Ibidem.

10. Sólo se va a inventariar un caballo tasado en 1.200 reales. Ibidem.

11. El cual se duplica si sumamos las importantes joyas y alhajas que son consideradas como una forma de inversión segura para poder hacer frente a los infortunios del negocio. Ibidem.

12. Era hijo de don Juan Pablos y de doña Paula Salán, vecinos ya difuntos de la villa de Villada y también conocemos las referencias en protocolos notariales a un hermano suyo, don Benito Pablos Salán, el cual figura como escribano de la villa y al que en 1786 le vende la parte de la casa de su madre. Id., Valentín Rodríguez Brizuela, Caja 853. 
1812, los cuales fueron muy fructíferos a nivel económico con un balance muy favorable que se refleja de forma muy clara en el alto valor conseguido del activo patrimonial, 735.695 reales, sobre los que pesan un reducido nivel de endeudamiento, tan sólo 17.423 reales, de ahí que el líquido sea de 718.272 reales $^{13}$. Pero lo realmente relevante es que el punto de partida es muy bajo, ya que las aportaciones al matrimonio del marido fueron sólo de 3.300 reales y las de la mujer 32.603 reales, en total sólo un 4,9\% del total patrimonial, y en cambio la mayor parte de estos bienes fueron conseguidos en esos 30 años de matrimonio, es decir fueron gananciales: 646.636 reales, lo que significa un $87,9 \%$ del total patrimonial ${ }^{14}$. Por lo tanto, es de nuevo la mujer la que aporta no sólo más bienes dotales y parafernales al núcleo familiar ${ }^{15}$, sino que también es la que transmite la herencia del negocio comercial de sus padres: la experiencia y sobre todo los contactos comerciales. Sólo de esta forma se puede dar explicación a este fuerte éxito de la nueva familia, Pablos Rodríguez, partiendo de niveles muy bajos, sobre todo por parte del esposo, tanto en bienes que consigue aportar al matrimonio, dotales y parafernales, como en su tradición familiar y experiencia comercial. Además, no hay que olvidar que este logro económico se corresponde con años de dificultades económicas y sociales, provocados tanto por las crisis económicas finiseculares y de comienzos del siglo como por los avatares políticos que trajeron consigo exacciones de géneros y contribuciones y empréstitos forzados.

No obstante, ello no fue óbice para el discurrir de forma favorable de un negocio con tienda abierta en León ciudad y asentado en la venta al por menor de libros $^{16}$, cacao y sobre todo de géneros textiles (bayetas, pañuelos, cintas, medias, paños), dentro de un radio de acción básicamente provincial y con ramificaciones hacia las provincias más próximas de Asturias (Pola de Siero, Cudillero), y Galicia (Santa Cristina de Rivas del Sil, etc.). Además, a comienzos del siglo XIX, 1802, don José Pablos Salán se dedicará también al préstamo de dinero a asturianos que bajaban a la siega a León y Castilla y al préstamo de grano a campesinos ${ }^{17}$ y finalmente, será el encargado, como apoderado, de gestionar el patrimonio y los negocios del Marquesado de San Vicente y Fonteoyuelo en León ${ }^{18}$. Sin embargo, estas

13. Id., Antonio Ginovés Martín, Caja 1011.

14. Ibidem.

15. Dotales aportó la cantidad de 5.500 reales en 1780 y en 1801 cuando fallece su madre heredó 26.003 reales. Id., Juan de Dios Fernández, Caja 944.

16. Predominan los de temática religiosa pero también encontramos libros de gramática latina y castellana, los "Vocabularios de Nebrija" y "El teatro Crítico de Feijoo". Id., Antonio Ginovés Martín, Caja 1011.

17. En 1802 hay un escritura de poder donde don José Pablos Salán hace referencia al cobro de deudas de vecinos del concejo de Lena y otros pueblos de Asturias de dinero en metálico que les prestó cuando bajaron a la siega. Yen el mismo año se localizan escrituras de obligación a favor del comerciante de trigo dado al fiado. Id., Tirso Días José, Caja 945.

18. Id., Juan de Dios Fernández, Caja 951. 
actividades crediticias, financieras, no tuvieron la entidad suficiente para poder eclipsar la gran fuerza del negocio comercial, tal como se analizará a continuación.

De este modo, en cuanto al estudio de la estructura de su fortuna, el grueso de sus bienes están formados por los bienes mobiliarios. los cuales representan un $76,3 \%$ del total de la riqueza patrimonial inventariada. Y dentro de éstos son los conceptos o partidas vinculadas directamente al comercio las más importantes. Así, el stock de productos comerciales existente en su tienda y almacén constituye la partida más relevante con un $26,8 \%$ en relación al activo comercial y un $43,7 \%$ del total de la riqueza mobiliaria. El dinero en efectivo (líquido) supondrá un 14,1\% en relación al activo, cantidad que es ligeramente incrementada si incluimos las joyas y objetos de oro y plata. Y finalmente, las deudas a favor de la casa provenientes de la actividad comercial (ventas mediante el sistema de obligación) sólo significarán el 7,4\% en relación al activo patrimonial ${ }^{19}$. Por lo tanto, el esquema es muy similar a los casos comparativos de la burguesía comercial vitoriana, navarra, valenciana, en el sentido de que es la venta de mercancías y no la inversión financiera la actividad básica de esta burguesía, aunque en nuestro caso los créditos a favor tengan un papel más secundario y sean los productos comerciales en stock la partida de mayor valoración, con los problemas que ello puede generar para el negocio familiar en el caso de que dichos productos no encuentren una rápida salida al mercado ${ }^{20}$.

También nuestra familia mostrará un especial interés por la compra de bienes raíces y dentro de los mismos los más atrayentes serán las inversiones en inmuebles urbanos, sobre todo lonjas y casas, donde poder asentar sus nego$\operatorname{cios}^{21}$. De este modo, aprovechando la coyuntura de la desamortización de Carlos IV a fines del siglo XVIII, la denominada de Godoy entre 1799 y 1808, don José Pablos Salan y su mujer consiguieron comprar un total de 12 casas pertenecientes a cofradías eclesiásticas y un molino harinero de tres ruedas en el término de San Andrés que tendrán una valoración en el inventario de 110.343 reales, lo que significará el $18,6 \%$ de su riqueza patrimonial ${ }^{22}$. Esta oportunidad

19. Cantidad que podría incrementarse significativamente si se incluyesen las ventas forzosas a las tropas de uno y otro bando sobre todo durante la Guerra de la Independencia. Pero debido a la fuente nos ha sido imposible desglosar tales cantidades de deudas.

20. Ver Angulo Morales, A., Del éxito en los negocios..., pp. 305-320. Franch Benavent, R., El capital comercial valenciano en el siglo XVIII, Valencia, 1989, p. 250 y Azcona Guerra, A. $M^{a}$., Comercio y comerciantes..., p. 307.

21. Lo mismo que sucedía con la burguesía valenciana, vitoriana, navarra o de Cádiz y Sevilla.

22. Las casas, algunas son casas-lonja como la que tenía en Puerta Obispo, las compra sobre todo en los años 1802-1803. Y además de las casas de León ciudad también comprará dos casas en la localidad cercana de Mansilla de las Mulas, dedicando una de ellas a mesón que dará en renta. Sobre la desamortización de Godoy en León ver trabajos de Lorenzana Fernández, A., el cual ya señalaba a don José Pablos Salán como uno de los mayores compradores, "Desamortización y transferencias de propiedad inmobiliaria en la ciudad de León a 
desamortizadora la aprovecharán también para hacerse con tierras de cereal (88 fanegas $)^{23}$ y cuatro prados, que hacen un total de cuatro fanegas, en el término de San Andrés de Rabanedo ${ }^{24}$. En total las tierras de labor que figuran en su inventario son tasadas en 30.220 reales, lo que representa tan sólo un 5,1\% del valor patrimonial total, pero nos muestra las inclinaciones de esta burguesía hacia este tipo de inversiones inmobiliarias consideradas muy atractivas no sólo por su alto grado de seguridad y su carácter rentista sino también por su fuerte sentido social como espejo del éxito en los negocios ${ }^{25}$. De ahí, que ante la nueva coyuntura favorable del mercado de propiedades inmobiliarias que abre la Desamortización de Godoy nuestra familia no dude en beneficiarse de la ocasión y se lance a la compra de estos bienes raíces en unos momentos donde el negocio comercial atravesaba un período de auge y donde la propia esposa recibe una importante inyección económica al ingresar a su hacienda familiar los bienes de la legítima materna ${ }^{26}$.

Una prueba más de este éxito comercial de la familia a finales del siglo XVIII y primera década del XIX será el interesante matrimonio de una sus hijas, Francisca Pablos, con el comerciante afincado ya en León, pero natural de Palencia, Valentín Bustamente, realizado el 26 de octubre de 1809 en la parroquia de San Martín ${ }^{27}$, con el que forma una compañía de comercio en menos de un año (julio de 1810) donde el suegro aporta la cantidad nada desdeñable de 200.000 reales (165.000 reales en géneros y libros de sus comercio y 35.000 en dine$\left.\mathrm{ro}^{28}\right)$. Se trata de nuevo de una compañía familiar "personalista" donde el peso del paterfamilias era el más relevante tanto a la hora de aportar fondos a la misma como a la hora de tomar decisiones y en el reparto de los dividendos ${ }^{29}$. Así, frente a los 200.000 reales ya descritos que aporta el suegro, don José Pablos Salán, el yerno, don Valentín Bustamantante sólo contribuirá con 55.000 reales en dinero efectivo, es decir un poco por debajo de la cuarta parte del capital

principios del siglo XIX, en Estudios Humanísticos. Y Aguado Cabezas, E., La desamortización de Mendizábal y Espartero en la provincia de León (1836-1851), León, 2002, pp. 77-87.

23. Situadas en el término de Arenillas, muy próxima a la villa natal palentina de Villada que anteriormente pertenecían a cofradías de Arenillas, compradas en 1796 y sobre todo en 1807. A.H.P.L. Antonio Ginovés Martín, Caja 1.011.

24. Tres de ellos pertenecientes junto con el molino ya descrito a la fundación de Doña María Josefa Romero sita en el convento de Santo Domingo de León, los cuales compró en 1804. Ibidem.

25. Angulo Morales, A., Del éxito en los negocios..., p. 332.

26. La madre muere, como ya se ha señalado, en 1801, y la hija hereda la cantidad de 32.603 reales. Y la mayoría de las compras de tierras y casas desamortizadas son realizadas entre 1802 y 1807. A.H.P.L, Juan de Dios Fernández, Caja 944 y Antonio Ginovés, Caja 1.011.

27. A.P.S.M., Libro de Casados № 6 (1801-1835).

28. A.H.P.L., Juan de Dios Fernández, Caja 951.

29. Al igual que sucedía en Valencia, Vitoria o el área marsellesa. Franch Benavent, R., EI capital comercial...; Angulo Morales, A., Del éxito en los negocios..., p. 225; Carriere, Ch., Négociants marseillais au XVIIle Siècle, Marsella, 1973, pp. 880-885. 
total $^{30}$. De ahí que se estipule que en el momento de repartir las ganancias éstas se hayan de dividir en cuatro partes y de éstas tres serán para don José y la restante para don Valentín compensándole de este modo el mayor trabajo que presta en el comercio "aunque por su capital no debiera sacar tanto interés" ${ }^{31}$.

Respecto a las condiciones y estilo de vida de la familia burguesa que nos ocupa se pueden señalar las siguientes características: en primer lugar, la escasa valoración que tienen estos bienes en relación con la riqueza mobiliaria, ya que únicamente alcanzarán los 13.048 reales, lo que supone sólo un 3\% de la riqueza mobiliaria. En segundo lugar, sorprende que sean los objetos de oro y plata, joyas y alhajas, los que tengan una mayor tasación por encima de la ropa ${ }^{32}$, los primeros un $43,7 \%$ y en cambio toda la ropa, tanto la personal, como la de cama y casa el $28,2 \%$. Esta predilección por los objetos de oro y plata es debida tanto al hecho ya señalado de buscar un seguro con respecto a los infortunios del negocio, ya que las joyas y alhajas se pueden convertir fácilmente en dinero líquido ante una situación comprometida o se pueden entregar en depósito para hacer frente a las deudas o impagos puntuales, como también a la tendencia a la ostentación en cuanto que sirven para exteriorizar el éxito económico y social de la familia. De ahí se explica que el mayor valor de tasación de estas joyas sean las que son utilizadas para un uso personal ${ }^{33}$. No obstante, a pesar de la escasa valoración de la ropa personal sí que apreciamos sin embargo en las pautas de consumo la presencia de las novedades tanto en las fibras textiles (algodón) como también en las prendas de vestir: chaquetas ${ }^{34}$. En tercer lugar, hemos de destacar la gran abundancia de bienes muebles que invaden todas las estancias de la casa (catres, arcas, arcones alacenas, escaparates, etc.), lo cual explica más su alta tasación que en realidad las novedades en los mismos ${ }^{35}$. Y finalmente, se ha de resaltar la nula presencia de libros para uso personal, a pesar de estar en contacto con los mismos debido a su comercio, y el gusto, ya genérico a todos los grupos sociales y también a la burguesía, por una decoración fundamentalmente religiosa, donde abundan los cuadros de santos, santas de su devoción ${ }^{36}$. Aunque también se advierte la presencia de nuevos elementos deco-

30. Ibidem.

31. Ibidem.

32. Normalmente era la ropa el concepto de mayor valor dentro de los ajuares de la burguesía. Ver Angulo Morales, A., Del éxito en los negocios...

33. Así como ejemplos se pueden citar un collar de perlas de la esposa valorado en 650 reales y una cadena de oro con un valor de 450 reales. A.H.P.L, Antonio Ginovés Martín, Caja 1.011.

34. Para una mayor información sobre este interesante tema del consumo de textiles ver trabajos del grupo de investigación "Consumo y comercialización de textiles en Castilla y Cantabria, 1750-1914", coordinado por el profesor Bartolomé Yun Casalilla.

35. Sólo aparece en la sala principal un canapé de tres asientos forrados en esparragón, valorado en 150 reales. A.H.P.L., Antonio Ginovés Martín, Caja 1.011.

36. Nuestra Señora del Mercado, etc., Ibidem. 
rativos: espejos, relojes de madera y cortinas tanto de esparragón (seda) como de la nueva fibra textil más barata que es el algodón ${ }^{37}$.

En definitiva, a través del estudio de los bienes que nos pueden informar aunque sea de forma muy genérica de las condiciones y estilo de vida, sí que observamos una tendencia en nuestra familia burguesa hacia una mayor comodidad y un mayor confort en sus formas de vida, pero en ningún momento se puede señalar que este tipo de lujo sea exagerado sino al contrario bastante moderado ${ }^{38}$.

El matrimonio formado por don José Pablos Salán y doña Ma Antonia Rodríguez de Brizuela tendrá un total de seis hijos, de los cuales van a sobrevivir a la muerte de la madre cinco $^{39}$. De ellos tres serán mujeres y dos varones. Como es lógico el paterfamilias diseñó estrategias matrimoniales muy marcadas para las hijas enlazando bien con familias de la burguesía profesional leonesa (como es el caso de Gabriela de Pablos que se va a casar con el escribano Félix Vinue$\mathrm{sa})^{40}$, o bien esposos conectados con el mundo comercial tanto en sus inicios (como ocurre con Francisca de Pablos que se casará, como ya se ha señalado, con el comerciante Valentín Bustamente, natural de la ciudad de Palencia ${ }^{41}$ ) o con miembros de familias ya consolidadas en León, aunque su procedencia fuese catalana, como sucede con Clara Pablos cuyo esposo es Atanasio Jolís, el hijo de una familia de origen catalán que establece su residencia y comercio en León (don José Jolís y doña Ángela Trabajo) ${ }^{42}$. Por lo tanto, queda clara la estra-

37. Así, por ejemplo, en la sala principal de su casa tienen cuatro cortinas de esparragón para cubrir los balcones tasadas en 50 reales. Ibidem.

38. Tendencia muy similar a la señalada para la burguesía valenciana y vitoriana. Angulo Morales, A., Del éxito en los negocios..., p. 324. Franch Benavent, R., El capital comercial...

39. Una de las hijas, Marina, falleció siendo párvula en 1799. A.P.S.M., Libro de enterramientos.

40. El matrimonio se celebró en la parroquia de San Martín el 12 de mayo de 1805. Id., Libro de casamientos № 6 (1801-1835). La dote de la hija fue de 24.433 reales cuyo desglose por interesante incluimos a continuación:

- muebles y un collar de perlas, 1.734 reales,

- ropas, 520 reales,

- por un catre pintado con su encordeladura, 172 reales,

- por la casa que habita en la calle de la Rúa, 14.812 reales,

- por el oficio de escribano numerario, 6.000 reales,

- por los costos de aprobación de los títulos en Madrid, papel gastado y propina de ministros 1.195 reales.

A.H.P.L., Antonio Ginovés Martín, Caja 1.011.

41. Casamiento que se realizó el 26 de octubre de 1809. La dote de la hija fue de 23.600 reales, de los cuales la mayor parte fueron en dinero 22.000 reales y el resto en un catre, colchones, sábanas, almohadones, cobertores de Palencia, colcha vieja y ropa de vestir interior y exterior. Ibidem.

42. Para una mayor información de estas familias catalanas ver comunicación de Bartolomé Bartolomé, J.M., "Hacer negocio en León: las familias catalanas ...". El casamiento se va a realizar el 21 de noviembre de 1811 en la parroquia de San Martín y la dote entregada a su hija será de 23.430 reales A.H.P.L., Antonio Ginovés Martín, Caja 1.011. 
tegia de cara a las hijas de enlazarlas preferentemente de forma endogámica con otras familias de comerciantes ${ }^{43}$.

Al mayor de los hijos varones se le encomienda un futuro mucho más arriesgado pero dentro del marco del negocio familiar: abrirse camino en América. Así, en 1802 se forma una compañía comercial entre padre e hijo aportando el primero en dinero y géneros de comercio (donde había también libros) la cantidad de 87.557 reales. Con la condición de que los benéficos obtenidos por el hijo, Pedro Manuel Pablos, en América fuesen repartidos por mitad ${ }^{44}$. Este distanciamiento con su hijo en América es el que motiva que más tarde se apoye en su yerno, Valentín Bustamente, para formar como ya se ha analizado una compañía de comercio y fortalecer su negocio familiar. Finalmente, el otro hijo varón, Carlos Pablos, es menor de edad en el momento de producirse el fallecimiento del padre.

En cambio no son tan claras las estrategias hereditarias, ya que únicamente su hijo varón menor de edad, Carlos, recibirá la mejora del quinto, repartiéndose la restante legítima paterna a partes iguales entre los cinco hijos. De este modo, la legítima paterna a heredar era de 344.484 reales $^{45}$, pero de la misma se descuentan con el objetivo de poder calcular el quinto donde iba la mejora la mitad de los dotales entregados y los costes de luto que se han dado a la viu$\mathrm{da}^{46}$ quedando 307.138 reales. Una vez calculado el quinto que son 61.427 reales se resta de los 307.138 reales y a la cantidad resultante, 245.711 reales, se vuelve a añadir los 35.731 reales de las dotes de las hijas. Siendo el resultado final de 281.442 reales para dividir a partes iguales entre los cinco hijos. De tal forma que a cada uno le tocan 56.288 reales y el menor Carlos además a esa cantidad añade la mejora el quinto que son 54.887 reales, en total 111.176 reales. En definitiva, al margen de los cálculos expuestos lo realmente cierto es que sus hijos heredan una cantidad muy superior a la que el padre consiguió apor-

43. Es lo que Alberto Angulo Morales denomina familias unificadoras, Del éxito en los negocios..., p. 122.

44. Incluso en ese mismo año mediante una escritura de poder don José Pablos Salan reconoce que da a su hijo géneros de comercio por un valor superior, de 92.000 reales, los cuales se hallan en Gijón dispuestos a ser embarcados a América. A.H.P.L., Tirso Díaz José, Caja 945. Sin embargo, en el momento del inventario y partijas del padre, 1.812, la cantidad se rebaja todavía más: 64.300 reales, debido a que "...los libros fueron de poca salida y corta estimación y aun caso de verificarse su venta no alcanzaría para los gastos de portes y transportes..." por lo que su voluntad era"... se le rebajase enteramente el importe de ellos, que según la factura ascendió a 23.252 reales...". Id., Antonio Ginovés Martín, Caja 1.011.

45. Desglosados de la siguiente forma:

-3.300 que aportó al matrimonio.

- 35.731 mitad de dotales entregados a las hijas.

- 305.453 de la mita de gananciales.

Ibidem.

46. En concreto se descuentan 35.731 reales de dotales y 1.614 reales del luto dado a la viuda. Ibidem. 
tar al matrimonio (56.288 reales frente 3.300 reales), pero dadas las circunstancias de la muerte del "paterfamilias", don José Pablos Salán en 1811, y tal como se habían diseñado las estrategias matrimoniales, hereditarias, etc., la única que podía seguir al frente del negocio familiar era la viuda apoyada en uno de sus yernos comerciante, don Valentín Bustamente.

\section{b.2. Fase de ruptura matrimonial: el papel relevante de la viuda}

La viuda, doña M ${ }^{a}$ Antonia Rodríguez de Brizuela, recibe en herencia una vez que fallece su esposo la cantidad de 373.787 reales, donde están incluidos la mitad de los dotales dados a las hijas. Esta cantidad supone un poco más de la mitad del activo patrimonial líquido familiar, en concreto el 52\% y se explica por el mayor ingreso de bienes de la esposa al matrimonio y sobre todo por el carácter ganancial de los bienes conseguidos, yendo a parar la mitad de los mismos a la mujer y no entrando en este momento en el reparto entre los hijos. Por lo tanto, la viuda consigue hacerse con la mitad de los bienes patrimoniales de la fami$\mathrm{lia}^{47}$. Ahora bien, el siguiente interrogante al que tenemos que dar respuesta es el siguiente: ¿la viuda continuó con el negocio familiar? y en caso afirmativo ¿cuál fue la importancia de los bienes que la entregaron en herencia de cara a esa actividad comercial? A través del análisis de la hijuela de la viuda hemos podido comprobar que la casi totalidad de los bienes que se dan a la viuda corresponden a los mobiliarios, el 95,9\%, pero lo más interesante es que así como las tierras de labor entregadas sólo suponen el 17\% respecto a las inventariadas en el patrimonio familiar, en cambio en las viviendas y dependencias complementarias (molino) se la va a dar un poco más de la mitad, el 66\%, y en los bienes de mayor valoración y relevancia del patrimonio familiar, los mobiliarios, la viuda consigue retener el 50,5\% $\%^{48}$. Pero es que además dentro de los bienes mobiliarios los más trascendentales para poder asegurar la continuidad en el comercio no se fragmentarán excesivamente incluyéndolos en la legítima paterna a repartir entre los cinco hijos sino que se volverá a respetar que en torno a la mitad sean recibidos por la viuda: el $47,5 \%$ de las deudas a favor, generadas por la actividad comercial, el $49,6 \%$ de los géneros en stock del comercio ${ }^{49}$ y el $45,9 \%$ en el dinero en efectivo. En definitiva, esta hijuela otorgada a la viuda no es un reparto aleatorio sino que respeta casi de forma escrupulosa el concepto de bienes gananciales y permite a la misma poder continuar con el negocio familiar. Además, se la dejará habitando en la misma casa y se le permitirá conservar la casi totalidad del mobiliario y objetos decorativos y hasta los textiles y objeto de plata que existían en la casa ${ }^{50}$. De ahí, que la viuda cuidará de su hijo menor y seguirá al frente del negocio familiar apoyándose, eso sí, en la colaboración,

47. A.H.P.L., Antonio Ginovés Martín, Caja 1.011.

48. Lo cual se correspondería con la mitad de los gananciales. Ibidem.

49. En estos géneros se hace la distinción entre los de primera salida, los libros y los más abundantes y de mayor tasación que son los corrientes. Ibidem.

50. En realidad recibe en herencia el 91,9\% de este tipo de bienes. Ibidem. 
mediante la correspondiente compañía de comercio, de su yerno, ya socio de la familia, don Valentín Bustamante.

Los siguientes años que transcurren desde la muerte del marido hasta la suya, en total 13 años, se pueden considerar de éxito económico desde el punto de vista de la compañía comercial familiar, ya que a finales del 1825, cuando fallece la viuda, el activo patrimonial de la misma ha subido a 555.299 reales, el grado de endeudamiento es muy reducido, tan sólo el 2,8\%, y el capital líquido es de 539.549 reales. Es decir, a pesar de ser años de fuertes dificultades (1812-1825), el crecimiento ha sido de un 44,3\% ${ }^{51}$. Fijándonos en la estructura de su riqueza patrimonial observamos dos grandes características: por una parte, ha conseguido incrementar el capital recibido en inmuebles urbanos más que en tierras de labor o ganadería, ya que ha comprado casas, una en León y otra en Mansilla de las Mulas, y la tasación de las mismas ha subido de 57.656 reales a 202.118 reales, un $177,5 \%$ donde hay que incluir también la lógica inflación experimentada por este tipo de bienes. Y por otra parte, donde también se ha producido un claro crecimiento es los bienes mobiliarios y dentro de los mismos en los conectados con el negocio comercial. Así, aumentará respecto a la herencia recibida levemente las deudas a favor del comercio y lo harán de forma más elevada en los géneros almacenados (de 97.704 reales a 103.483 reales) y sobre todo el dinero líquido que pasará de 47.547 reales a 103.199 reales, un $117 \%$ de incremento ${ }^{52}$. Además, esta tendencia nos reafirma la idea de éxito en la compañía comercial durante los años descritos del primer tercio del siglo XIX ya que se dan salida a géneros en stock que son cobrados sin problemas no aumentando las deudas a favor.

También se aprecia una mejoría a nivel global en los bienes que nos hablan de las condiciones y estilo de vida, ya que se ha producido un incremento en su tasación respecto a los anteriores del patrimonio familiar y los recibidos en herencia por la viuda, que, como señalábamos, eran casi los mismos, pasando de unos 13.000 reales a 22.116 reales $^{53}$. No obstante, en un análisis más pormenorizado observamos que más que en la decoración, mobiliario de la casa o útiles de cocina la mejoría va a producirse en los textiles, fundamentalmente en la ropa de casa y sobre todo de cama ${ }^{54}$, en los objetos de oro y plata ${ }^{55}$ y en la posesión de libros ${ }^{56}$.

51. Id., Santiago Gallego, Caja 1.097.

52. Ibidem.

53. Ibidem.

54. En la ropa de casa destacan las tablas de manteles y también novedades como las servilletas de algodón. Y en la ropa de cama sobresale especialmente por su cantidad más que por sus novedades: sábanas de lienzo, cobertores de Palencia, colchas manchegas, etc. Ibidem.

55. La plata se tasa en 6.992 reales, cantidad que supone más que el doble de la heredada por la viuda y superior también a la que poseía el matrimonio, y de ella la mayor parte está formada por objetos de cubertería, bandejas, cubiertos, salvillas, y únicamente 1.812 reales serán de alhajas de uso personal (pendientes, y sobre todo collares de perlas). Ibidem.

56. Respecto a los libros es muy interesante destacar que en inventario post-mortem se relacionan abundantes libros que son valorados en 3.065 reales y que según se dice eran "...sepa- 
Este papel activo de la viuda al frente del negocio familiar en compañía con su yerno determina que en el momento de su fallecimiento sus hijos reciban una herencia por el concepto de legítima materna de 105.997 reales cada uno de los cinco, es decir casi el doble de la hijuela paterna, 56.288 reales. No obstante, el único hijo varón, don Carlos, presente en la ciudad de León, todavía era menor de edad y por lo que conocemos no continuará el negocio familiar y únicamente su yerno, don Valentín Bustamante, será quien recoja dicha tradición ${ }^{57}$ enlazando uno de sus hijos en 1832 con la importante familia de comerciantes catalanes asentados ya en León, los Selva ${ }^{58}$.

\section{La familia Hernández de Medina-Fernández}

\section{a) Orígenes y asentamiento en León}

A mediados del siglo XVIII una de las familias de comerciantes de la ciudad leonesa era la formada por don Francisco San Martín y doña Ángela Fernández, los cuales se habían casado en la parroquia de San Martín en 174959. La muerte del marido por los años cincuenta, don Francisco, facilita la Ilegada y asentamiento en León de un nuevo hombre dispuesto a hacerse cargo del negocio de don Francisco y a aprovechar su tradición comercial intentando hacer fortuna. Se trata de Miguel Hernández de Medina, vecino de la localidad castellana de Béjar, hijo de don Juan Hernández de Medina y de doña Teodora Jiménez Rojas, vecinos de Béjar ${ }^{60}$. Aunque desconocemos las razones que conducen a esta unión matrimonial, quizás estén conectadas con los contactos y negocios comerciales del marido, lo cierto es que se realiza este matrimonio entre la viuda del comerciante leonés, doña Ángela Fernández y don Miguel Hernández de Medina, con la particularidad de que él no aporta ningún bien al matrimonio y

rados del comercio y de la difunta y se hallaban en la habitación alta". Ibidem. Lo más probable es que sean los propios libros que anteriormente estaban en la tienda y como no se conseguía darles salida pasaron a ser incorporados a la biblioteca personal de la viuda, ya que a simple vista los títulos coinciden. Aunque ello exigiría un estudio más detenido.

57. Don Valentín Bustamante quien por los años 20 del siglo XIX comprara bienes raíces en Villaobispo de las Regueras y relevará a su suegro en el cargo de mayordomo de la Marquesa de San Vicente y Fuenteoyuelo.. Id., José Tirso Días, Caja 959.

58. El 3 de diciembre de 1832 se produjo el casamiento de Manuel Bustamante con Florentina Selva, nieta de Ramón Selva y María Castañer. A.P.S.M., Libro de Casados, № 6 (1801-1835).

59. Don Francisco San Martín era viudo de Jerónima Lozano y doña Ángela Fernández era hija de don Juan Antonio Fernández y Ana Fernández, vecinos de la ciudad de León. El casamiento tuvo lugar el 18 de febrero de 1749. Y según el Catastro del Marqués de la Ensenada en 1752 figura como un comerciante de tienda de "joyería, especería e hierro" ingresando al año 3.300 reales. Además es visitador de las rentas del tabaco, ingresando por este concepto al año 4.015 reales. Su estado civil es casado y tiene dos criados y tres hijas menores de 18 años. A.P.S.M., Libro de Casados, № 4 (1725-1763). A.H.P.L., Catastro del Marqués de la Ensenada. Caja 8.279.

60. A.H.P.L., Félix González Mérida, Caja 867. 
en cambio ella lleva bienes estimados en una cantidad de 30.000 reales $^{61}$, lo que de nuevo nos vuelve a señalar el carácter interesado de la unión ya que ella trata de buscar un apoyo masculino para sacar adelante el negocio que parecía atravesar por dificultades y él lógicamente una buena oportunidad.

\section{b) La familia y su dinámica: el éxito en los negocios.}

Partiendo de un capital inicial de tan sólo 30.000 reales, hijuela de la viuda, la nueva familia que se creó va a saber aprovechar la relaciones comerciales ya establecidas por don Francisco San Martín y las oportunidades ofrecidas en el último tercio del siglo XVIII y de este modo en 1799, año en que fallece don Miguel Hernández de Medina, el valor patrimonial de la familia es de 767.322 reales. De ellos el pasivo es de sólo un 11,2\% y el capital líquido asciende a la cantidad de 683.387 reales $^{62}$. Además, con la relevante particularidad de que se tratan de bienes conseguidos durante el matrimonio, gananciales, un total de 651.386 reales, lo que significa el $84,9 \%$ del total patrimonial. Por lo tanto, el balance no puede ser más positivo desde el punto de vista económico donde la actividad principal es el comercio de tienda abierta de productos variados: donde junto al tradicional y más importante del hierro (materiales de chatarrería fina, ferretería ${ }^{63}$ ) se une el de licores, aceite, cera e incluso textiles. Un comercio que surte de forma directa a la ciudad de León y en general a toda la provincia y de forma indirecta a otros comerciantes castellanos ( Valladolid, Zamora, Salamanca -Bejar-, Palencia), asturianos (Oviedo) y de Zaragoza ${ }^{64}$. Por las deudas en contra también podemos acercarnos a los centros de abastecimiento de mercancías, destacando Inglaterra y en concreto Birmingan ${ }^{65}$.

61. En el testamento del marido, don Miguel Hernández de Medina, éste declara que cuando contrajo matrimonio con su actual mujer "...ésta se hallaba viuda en su casa con un poco de comercio y entonces no se formó escritura de dote, ni la hice resguardo alguno de sus bienes ya que aunque en mi anterior testamento manifesté que el caudal que a mi concepto pudo traer cuando contrajo conmigo matrimonio ascendería a 45.000 reales, debe entenderse que esta declaración la hice impelido de varios fines piadosos que tuve presentes, pero ahora para el descargo de mi conciencia y por estado en que me hallo debo declarar real y verdaderamente que al tiempo y cuando contraje matrimonio con mi querida esposa reflexionado con la mayor madurez pudo traer de caudal como unos 30.000 reales en tres casas comercio y ajuares . Y prevengo que dichas tres casas tenían contra sí ciertos censos que sus capitales ascendían a 9.900 reales los cuales redimí durante nuestro matrimonio..." "...Yo cuando tomé matrimonio no llevé bienes especiales...". Ibidem.

62. Es decir entraría dentro de la rica burguesía leonesa y de la mayoría de la burguesía vitoriana. Ver Rubio Pérez, L., La burguesía maragata, León, 1995, pp. 176-177 y Angulo Morales, A., Del éxito en los negocios..., p. 297.

63. Cuchillos, navajas, hebillas, botones y escopetas inglesas, piezas para relojes, chatarrería fina de acero, cristal inglés, etc. A.H.P.L., Félix González Mérida, Caja 867.

64. Ibidem.

65. No obstante, también figuran relaciones con las herrerías leonesas, sobre todo las bercianas. Ibidem. 
En cuanto a la estructura de la fortuna familiar es la riqueza mobiliaria con 524.729 reales, lo que representa el $82,9 \%$ del total patrimonial, la que sobresale como es lógico muy por encima de los bienes raíces y de la ganadería. Y dentro de la misma los predominantes serán los conceptos vinculados directamente al negocio comercial. Así, los géneros almacenados, en stock, representan el 71,6 de los bienes mobiliarios, el 49\% del capital activo. Las deudas a favor del comercio el $17,2 \%$ y 11,8 respectivamente. $Y$ el dinero en efectivo tan sólo el 1,3\% de los bienes mobiliarios, el cual se incrementa al 5,4\% si incluimos las joyas o alhajas. Por lo tanto, este mayor peso de estos conceptos no es nada novedoso a nivel comparativo al tratarse de una burguesía comercial ${ }^{66}$, pero sí que causa cierta preocupación, igual que ocurría con la familia Pablos Salán ya analizada anteriormente, la gran presencia de géneros del comercio almacenados y la escasa liquidez monetaria, lo cual podría comprometer el futuro del negocio familiar.

Siguiendo las mismas pautas que sus homólogos tampoco descuidarán sus inversiones en bienes raíces, tierras y sobre todo inmuebles urbanos, consideradas éstos tan vitales para el buen funcionamiento de sus negocios y en general inversiones seguras y el medio de poder echar raíces y poder promocionar en la sociedad leonesa. Así, las tierras de labor adquiridas en los términos de pueblos próximos a León (Villanueva del Condado, Vegas del Condado, San Cipriano del Condado, Lorenzana) serán de cereal (24 fanegas) y las más ricas de linares y prados (en total 14 fanegas). Su tasación global será de 27.647 reales, un 4,4\% del total patrimonial. En cambio, las casas que poseen en León ciudad se valorarán en 80.470 reales, un $12,7 \%$ del global patrimonial ${ }^{67}$.

En los bienes mobiliarios que nos informan de las condiciones y estilo de vida se aprecia por una parte, un aumento de su tasación con respecto a la anterior familia analizada, situándose en 43.540 reales, lo cual no quita que sigan representando una mínima parte de todos los bienes mobiliarios, el 8,4\%. Y por otra parte, lo más interesante es remarcar cómo la mayor valoración se produce en todo tipo de bienes, pero sobre todo en las joyas y alhajas ${ }^{68}$, la ropa, fundamentalmente la personal ${ }^{69}$ y en los útiles de cocina ${ }^{70}$.

66. Ver Angulo Morales, A., Del éxito en los negocios..., pp. 305-320. Franch Benavent, R., el capital comercial valenciano en el siglo XVIII, Valencia, 1989, p. 250 y Azcona Guerra, A. $M^{\text {a. }}$, Comercio y comerciantes..., p. 307.

67. A.H.P.L., Félix González Mérida, Caja 867.

68. En total la valoración de estos objetos de oro, plata, diamantes y perlas es de 21.760 reales, de los cuales el predominio es de artículos de cuberterías, 17.183 reales, y el resto de uso personal: collares, cruces, relicarios. Ibidem.

69. Ésta con 7.473 reales es la de mayor tasación y además en ella encontramos las novedades en las prendas de vestir masculina y en las fibras textiles con la llegada del algodón: calzones de pana negro y azules, chalecos y chaquetas de algodón, etc. Ibidem.

70. Con calderas y ollas de cobre. Ibidem. 
En el transcurrir de sus días y negocios la familia analizada no se decantó por buscar socios y formar las frecuentes compañías de comercio con familiares ya que no tenemos noticias de las mismas. Tampoco se observa una estrategia muy marcada de cara al futuro de sus hijos. La viuda trajo del anterior matrimonio una hija, $M^{a}$ Cruz San Martín ${ }^{71}$ que en el momento de su matrimonio con don Francisco Javier Benayas, vecino de Benavente, sus padres le concedieron una dote de 33.00 reales $^{72}$. Y del nuevo matrimonio el resultado fueron tres hijos varones: el primero Pedro Antonio se va a casar con Paula Álvarez vecina de Zamora, residiendo en esta ciudad donde ejercerá también de comerciante, pero en ningún momento según nos consta se va a asociar con su padre y recibió en concepto de dote 34.678 reales $^{73}$. El segundo, Manuel Zoilo, fue encaminado hacia los estudios religiosos, siendo primero cura de Urdiales y más tarde arcediano de Carballeda, gastándose en sus estudios la cantidad de 61.791 reales $^{74}$. Y el tercero, es Tomás el cual se casará tres años después de la muerte del padre, en 1803, con María Casas y residirá en León ${ }^{75}$, siendo el hijo que se encargará de seguir la trayectoria del negocio familiar. De este modo, sí que en el testamento se observa una cierta preocupación por este último hijo ya que al final el padre le mejora en el tercio y remanente del quinto de sus bienes junto a su hermano religioso, pero con la condición de que la mejora del hermano religioso, don Manuel Zoilo, se entienda descontando los gastos efectuados en su formación ${ }^{76}$. Sin embargo, en el momento de efectuar las partijas éstas se realizan erróneamente y de los 86.063 reales que quedan del tercio y remante del quinto 50.000 reales se conceden y añaden al hermano religioso, don Manuel, cuando ya previamente se han descontado 61.000 reales por este concepto en los gananciales del padre y sólo 36.063 reales son los que se va a añadir al hijo don Tomás cuando se le tendrían que haber adjudicado la totalidad : los 86.063 reales. Con lo cual el resultado final es que el hijo que más bienes recibe es don Manuel, un total de 129.609 reales y sin descontarle nada de los 61.791 ya gastados en su formación religiosa, seguido de don Tomás, 115.770 reales y finalmente, don Pedro con 80.209 reales $^{77}$. No obstante, a la

71. Había sido bautizado el 13 de junio de 1750 en la parroquia de San Martín.

72. El matrimonio se realizó el 15 de mayo de 1785. El alto valor de la dote nos refleja la buena marcha ya por esos años ochenta del siglo XVIII del negocio familiar. A.P.S.M., Libro Casados № 5. A.H.P.L., Félix González Mérida, Caja 867.

73. A.H.P.L., Félix González Mérida, Caja 867.

74. Ibidem.

75. El casamiento tuvo lugar el 1 de septiembre de 1803. Ella era natural de Medina de Rioseco y sus padres eran Don Miguel de Casas y doña Catalina Puelles. Los Puelles habían enlazado anteriormente, a fines del siglo XVIII, con la importante familia leonesa dedicada también al comercio, los Fernández Chicarro. A.P.S.M. Libro Casados № 6.

76. "...advirtiendo que la mejor que hago en el don Manuel quiero se entienda de los gastos que tengo suplidos por el que dejo arriba manifestados y en las cuentas que quepa en dicha mejora del tercio y remanente del quinto quiero y es mi voluntad entre solo mi hijo don Tomás fiado siempre en que me encomiende a Dios...". A.H.P.L., Félix González Mérida, Caja 867.

77. Ibidem. 
muerte del padre, don Tomás será el que permanezca en la casa familiar junto con su madre, uniendo su hijuela paterna a la de su madre, un total de 441.629 rea$\operatorname{les}^{78}$ y haciéndose cargo del negocio y también de la administración de los bienes raíces de la madre ${ }^{79}$. De este modo, aunque en los bienes que correspondieron en la partija paterna a don Tomás no se aprecia un favoritismo para que hereden los más conectados con el negocio comercial ${ }^{80}$, sin embargo, al hacerse cargo del mismo junto a su madre viuda va a recibir por parte de ésta un trato de favor respecto a sus hermanos, ya que, por una parte, la madre le mejorará en 11.000 reales de vellón. Y por otra parte, le concede las ganancias del comercio y las rentas de los citados años que estuvieron juntos.

\section{Conclusiones}

La llegada y asentamiento de estos comerciantes de origen castellano se produce aprovechando la coyuntura del mercado matrimonial: mediante el casamiento con una viuda o una hija de un comerciante leonés. De ese modo, se beneficiarán más que del volumen comercial heredado de las redes de clientela y fundamentalmente de la tradición de la casa, aspectos vitales para un comerciante y donde era muy difícil introducirse.

Una vez establecidos en León estos comerciantes van a conseguir importantes éxitos económicos, a pesar de tener que desarrollar su actividad en períodos de dificultades económicas, políticas, etc., pero de nuevo demostraron una gran capacidad de adaptación a las nuevas coyunturas, sobre todo a las favorables a nivel demográfico y de demanda de productos de los años 70 y 80 del siglo $\mathrm{XVIII}^{81}$, sabiendo también sacar partido a las mismas, como lo demuestra la adquisición de bienes raíces en la desamortización denominada de Godoy.

El tipo de burguesía a que dan lugar es un modelo que encaja más en el descrito de la burguesía comercial como la valenciana, vitoriana o navarra que en

78. Entre gananciales, bienes que aportó al matrimonio (30.000 reales) y 85.936 reales que se le adjudicaron para el pago de las deudas. Ibidem.

79. En el propio testamento la madre declara: "... que los bienes y efectos que se me adjudicaron por mis dotales y mitad de haber en la partija y división de los que quedaron al fallecimiento del citado don Miguel mi difunto marido han estado y están unidos en el comercio con los de don Tomás, mi hijo que está en mi compañía y al cuidado de éste la recaudación y administración de los raíces que me correspondieron...". Id., Juan de Dios Fernández, Caja 947.

80. De los géneros comerciales sólo recibe un $19,4 \%$, de las deudas a favor del comercio un $12,5 \%$ y de las joyas y alhajas un 9,6\%. Félix González Mérida, Caja 867.

81. Tal como muy bien demuestra José $M^{a}$ Pérez García para el campesinado de la Vega Baja del Esla leonesa sería esta fase de 1760/89 la de los mejores momentos del modelo agrario analizado donde los elementos positivos superan con creces a los negativos, no siendo sorprendente que fuese durante esta fase cuando habríamos asistido a la mejor etapa de acumulación de capital en esta estructura agraria. José Pérez García, J.M., "Evolución de los niveles de vida en la Vega Baja del Esla entre 1700 y 1850", en Un modelo social leonés en crecimiento: La Vega Baja del Esla entre 1700 y 1850, León, 1998, pp. 160-170. 
el de la financiera del sur de España (Cádiz, etc.). De todos modos, un aspecto distinto y preocupante es la fuerte presencia y alto valor en relación con el activo de los géneros de comercio almacenados, lo cual podría comprometer el desarrollo de estas casas comerciales.

Estas nuevas familias se insertarán plenamente en la sociedad leonesa a través del enlace matrimonial de sus hijos con miembros de la burguesía profesional de fuerte raigambre o con miembros de la burguesía comercial que están también en sus inicios o ya establecidos sólidamente en la sociedad leonesa aunque su origen fuese catalán. También la salida religiosa será una de las vías preferidas para sus hijos. Por lo tanto, vuelve a predominar el concepto de familias unificadoras más que rectoras.

Tampoco se descuidará el relevante papel de las viudas una vez que fallece el "paterfamilias" de cara a hacerse cargo del negocio familiar y las estrategias de mejoras hereditarias encaminadas a favorecer a uno de los hijos, particularmente el encargado de continuar con el negocio.

Finalmente, no observamos una de sus marcas del triunfo: la creación de mayorazgos $^{82}$, ni tampoco su interés por el control político aunque fuese sólo a nivel municipal.

82. Según Angulo Morales, A., Del éxito en los negocios..., pp. 372-380. 

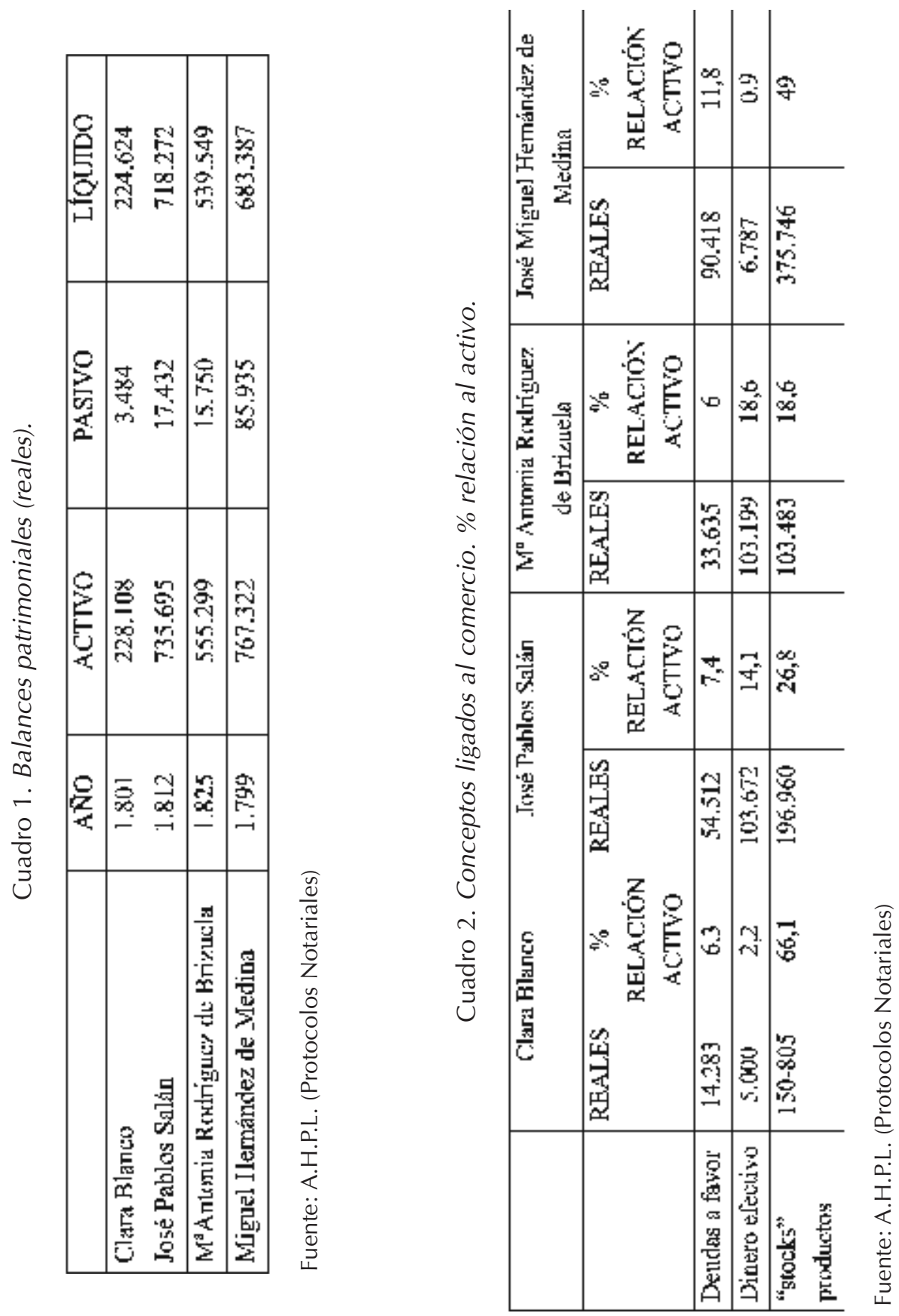
COMERCIANTES DE ORIGEN CASTELLANO EN LEÓN

$\frac{1}{8}$

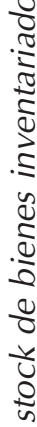

$\frac{9}{8}$

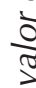

$\frac{1}{2}$

竞

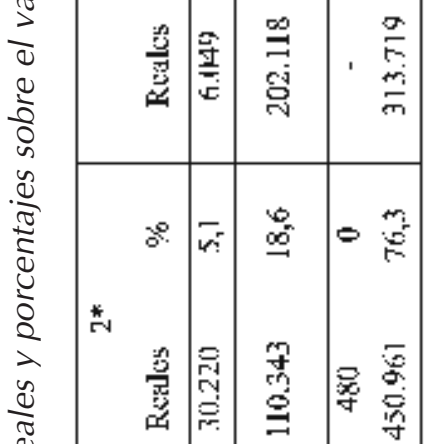

อ

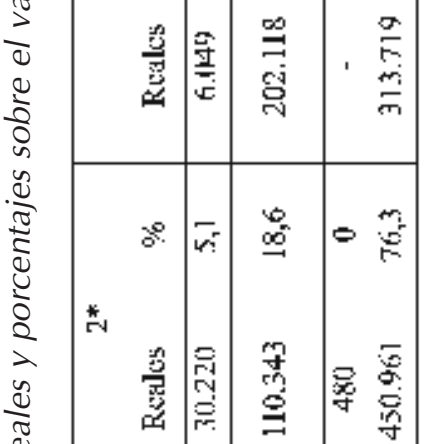

ฮี

ఏ

$\sqrt[\frac{2}{2}]{\frac{2}{2}}$

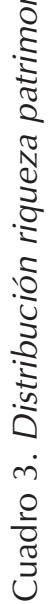

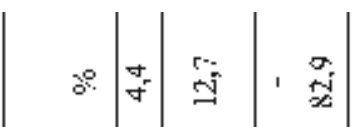 \\ 莳

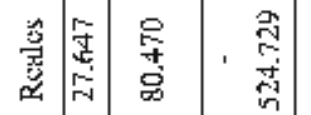

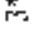

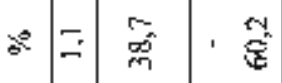

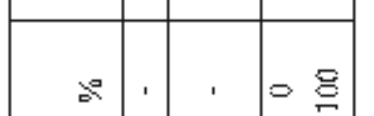

$\pm$

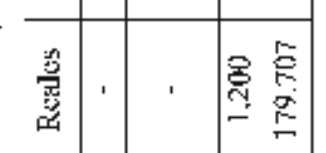

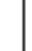

$\frac{\sqrt{2}}{3}$

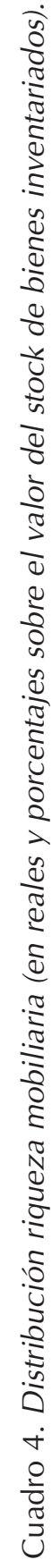

*

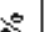

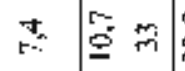

min

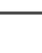

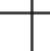
- N

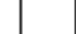

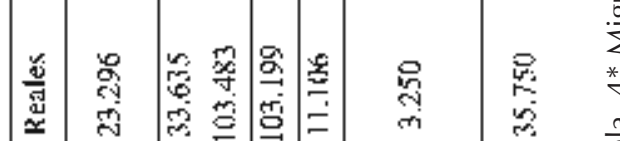

$\simeq$ ल

$\frac{0}{0}$

$\frac{1}{2}$
$\frac{0}{20}$
$\frac{20}{2}$
$\frac{1}{2}$
$\frac{\pi}{2}$
$\frac{0}{2}$
$\frac{0}{2}$
$\frac{1}{2}$

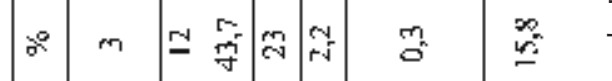

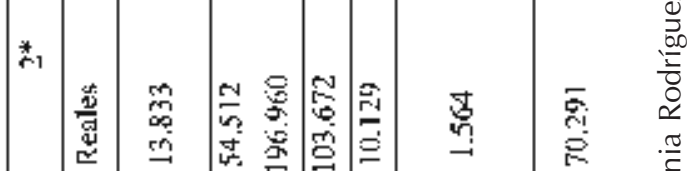

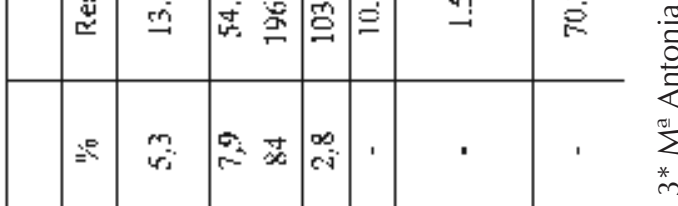

.

*

$\frac{\dot{\pi}}{\sqrt{\frac{\pi}{\pi}}} \cdot \frac{\sqrt{\pi}}{\frac{\pi}{\pi}}$

응

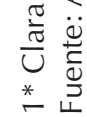


JUAN MANUEL BARTOLOMÉ BARTOLOMÉ

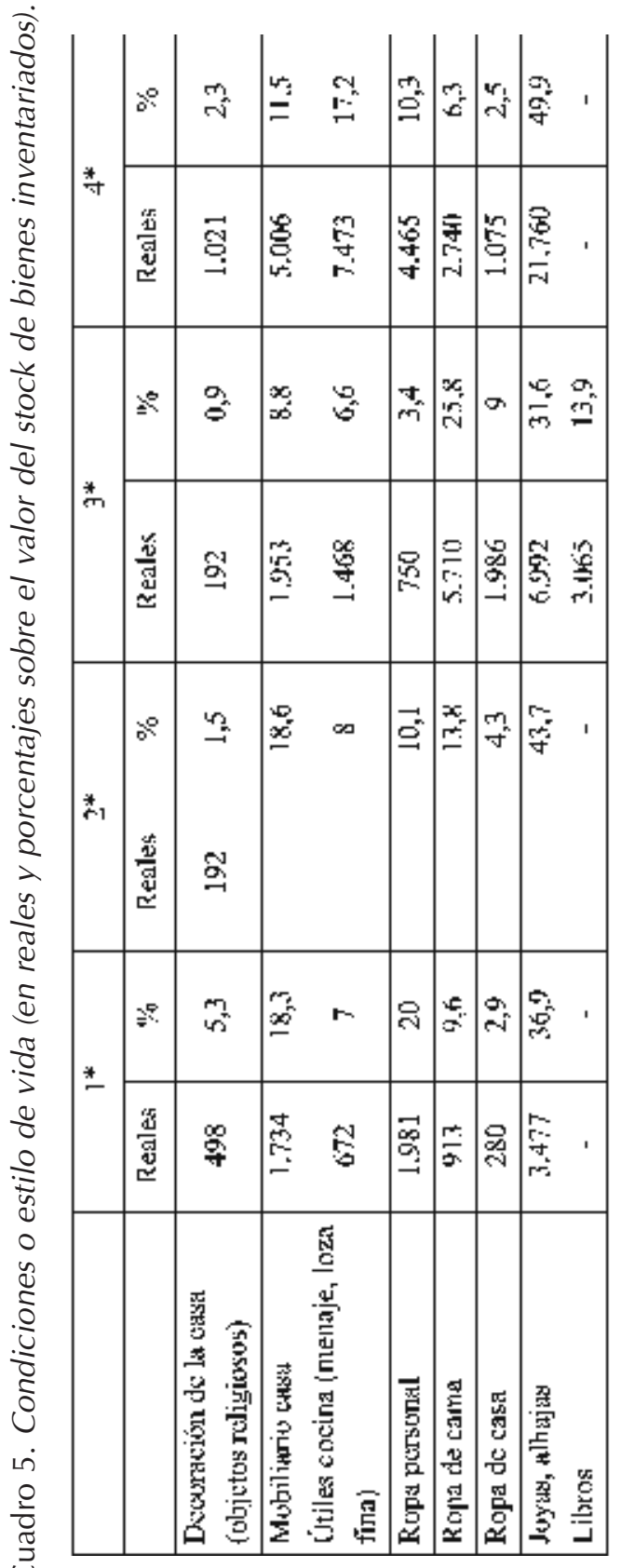

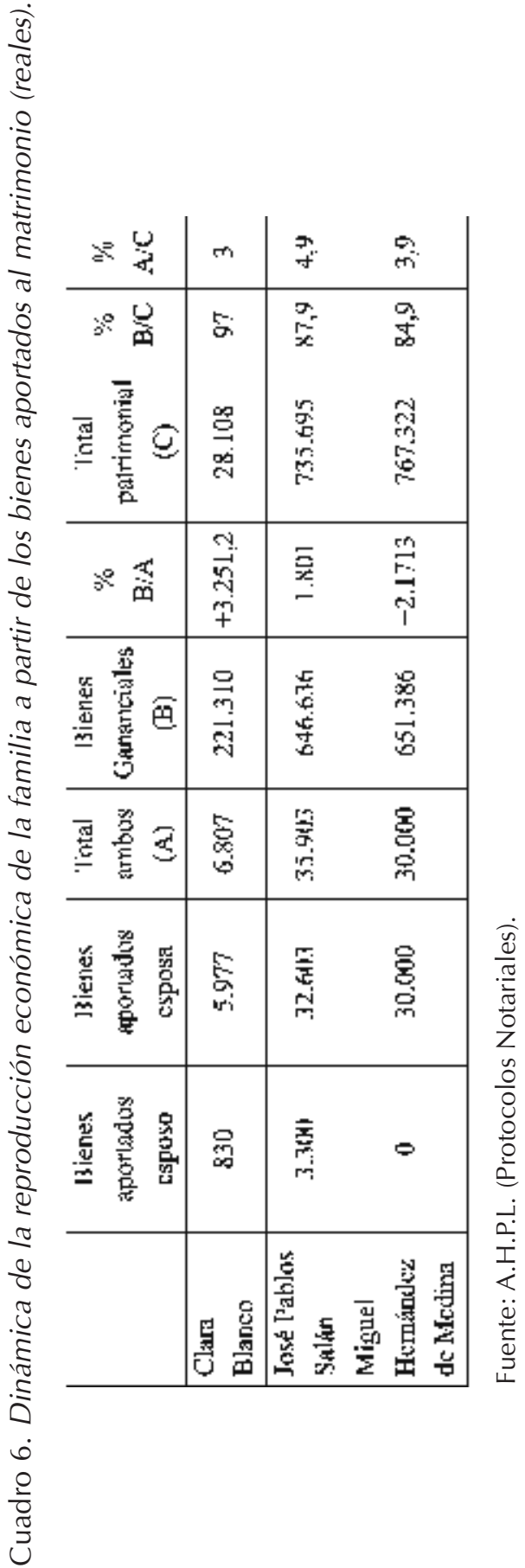

BROCAR, 28 (2004) 145-166 
COMERCIANTES DE ORIGEN CASTELLANO EN LEÓN

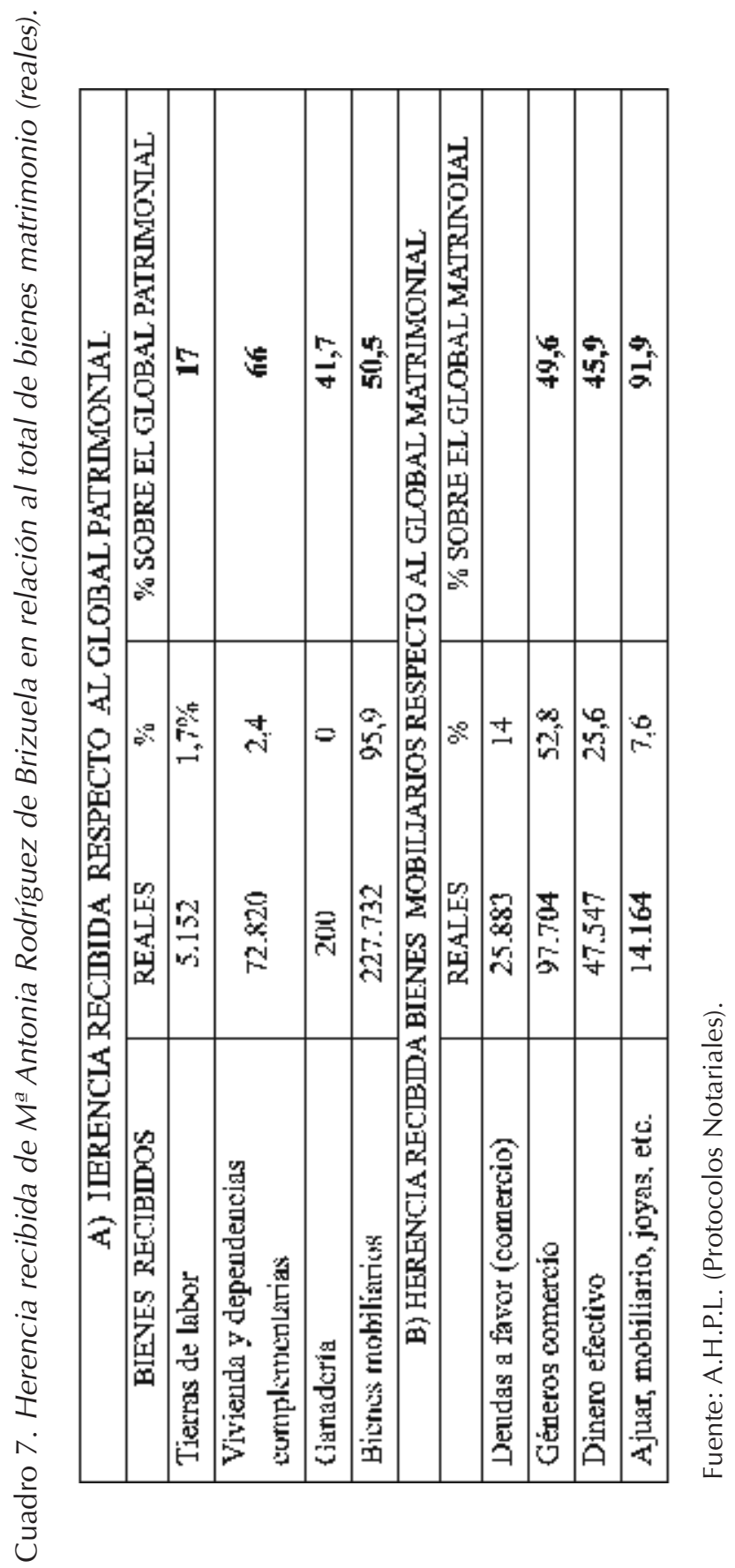


Cuadro 8. Familia Pablos Salán - Rodríguez.

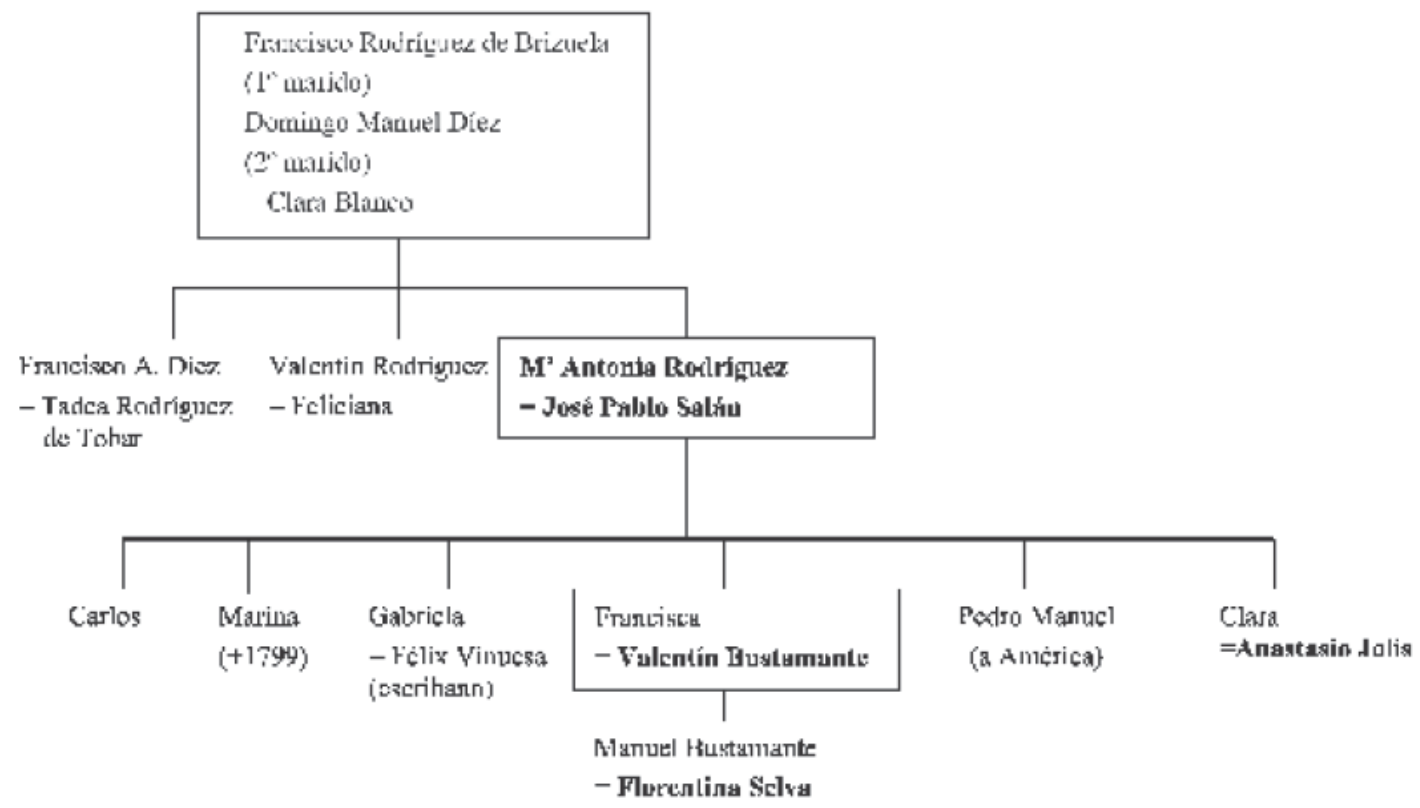

Cuadro 9. Familia Hernández Medina - Fernández.

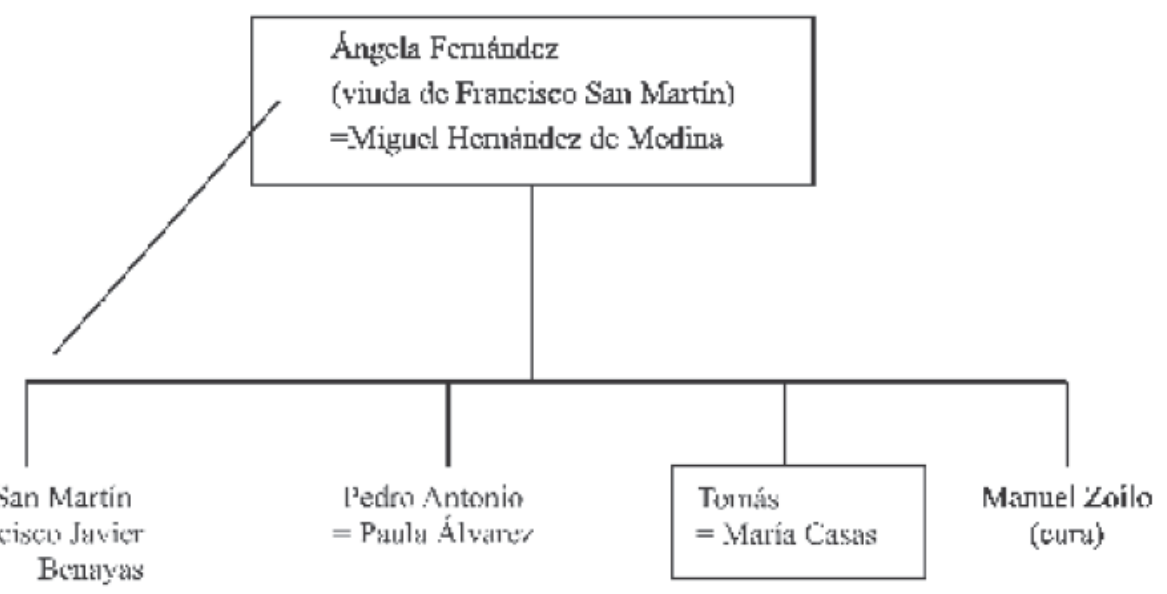

